\title{
Effect of Sapindus trifoliatus on hyperalgesic in vivo migraine models
}

D.K. Arulmozhi ${ }^{1,2}$ A. Veeranjaneyulu', S.L. Bodhankar ${ }^{2}$ and S.K. Arora ${ }^{1}$

\author{
${ }^{1}$ New Chemical Entity Research, Lupin Research Park, Village Nande, Taluk Mulshi, \\ Pune, Maharashtra, India \\ ${ }^{2}$ Department of Pharmacology, Bharati Vidyapeeth, Poona College of Pharmacy, \\ Pune, Maharashtra, India
}

\author{
Correspondence \\ D.K. Arulmozhi \\ Department of Pharmacology \\ New Chemical Entity Research \\ Lupin Research Park \\ Village Nande, Taluk Mulshi \\ Pune 411-042 \\ Maharashtra \\ India \\ Fax: +91-20-512-6298 \\ E-mail: adk_bits@yahoo.com
}

Received April 5, 2004

Accepted January 18, 2005

\begin{abstract}
Phytotherapies have offered alternative sources of therapy for migraine and gained much importance in prophylactic treatment. Sapindus trifoliatus is a medium-sized deciduous tree growing wild in south India that belongs to the family Sapindaceae. The pericarp is reported for various medicinal properties. A thick aqueous solution of the pericarp is used for the treatment of hemicrania, hysteria or epilepsy in folklore medicine. We have investigated the antihyperalgesic effects of the lyophilized aqueous extract of $S$. trifoliatus in animal models predictive of experimental migraine models using morphine withdrawal-induced hyperalgesia on the hot-plate test and on $0.3 \%$ acetic acid-induced abdominal constrictions in adult male Swiss albino mice. The extract significantly $(\mathrm{N}=$ $10, \mathrm{P}<0.05)$ increased the licking latency in the hot-plate test when administered ip at $10 \mathrm{mg} / \mathrm{kg}(6.70 \pm 0.39 \mathrm{~s}$ in saline control vs 18.76 $\pm 0.96 \mathrm{~s}$ in S. trifoliatus-treated animals) and significantly $(\mathrm{N}=10, \mathrm{P}$ $<0.001)$ reduced the abdominal constrictions when administered ip at 2 and $10 \mathrm{mg} / \mathrm{kg}(40.20 \pm 1.36$ in saline control vs $30.20 \pm 1.33$ and $23.00 \pm 0.98$ for 2 and $10 \mathrm{mg} / \mathrm{kg}$, ip, respectively, in S. trifoliatustreated animals). Furthermore, when administered $i p$ at 20 and 100 $\mathrm{mg} / \mathrm{kg}$, the extract significantly $(\mathrm{N}=10, \mathrm{P}<0.05)$ inhibited the apomorphine-induced climbing behavior in mice (climbing duration $15.75 \pm 5.0 \mathrm{~min}$ for saline control $v s \mathrm{11.4} \pm 1.28$ and $3.9 \pm 1.71 \mathrm{~min}$ for 20 and $100 \mathrm{mg} / \mathrm{kg}$, respectively, in S. trifoliatus-treated animals). In receptor radioligand-binding studies, the extract exhibited affinity towards $\mathrm{D}_{2}$ receptors. The findings suggest that dopamine $\mathrm{D}_{2}$ antagonism could be the mechanism involved in the antihyperalgesic activity of the aqueous extract of $S$. trifoliatus.
\end{abstract}

Key words

- Sapindus trifoliatus

- Hyperalgesia

- Migraine

- Dopamine

- $\mathrm{D}_{2}$ receptor

- Morphine withdrawal

\section{Introduction}

Migraine is a common, chronic, incapacitating neurovascular disorder characterized by attacks of severe headache, autonomic nervous system dysfunction, and, in some patients, by an aura involving neuro- logical symptoms (1). The drugs used for the treatment of migraine can be divided into two groups: agents that abolish the acute migraine headache and agents aimed at its prevention. In the last decade there has been a tremendous progress in the acute therapy of migraine, with sumatriptan, an agent be- 
longing to a new class of drugs now known as $5-\mathrm{HT}_{1 \mathrm{~B} / 1 \mathrm{D}}$ receptor agonists, being in the lead $(2,3)$. The success of sumatriptan in migraine therapy elicited further interest in research in the field of migraine. Currently, prophylactic treatments for migraine include calcium channel blockers, 5- $\mathrm{HT}_{2}$ receptor antagonists, beta adrenoceptor blockers, dopamine antagonists, and $\gamma$-amino butyric acid agonists $(4,5)$. Unfortunately, many of these treatments are nonspecific and not always effective.

Sapindus trifoliatus (ST) is a mediumsized deciduous tree growing wild in south India that belongs to the family Sapindaceae. It is known locally as soapnut tree. The plant has been reported for its high content of saponins and sugars. The saponin moiety is characterized as hederagenin group of glycosides. The pericarp is reported for various medicinal properties. It is regarded as a tonic, stomachic, spermicidal, and in the treatment of hemicrania (6-8). A thick aqueous solution of the pericarp is used for the treatment of hemicrania, hysteria or epilepsy (8). It is evident from the literature that plants like feverfew (Tanacetum parthenium), which is known for migraine prophylaxis, have antinociceptive and anti-inflammatory effects (9) in animal models of pain and inflammation. Since intranasally applied ST is used for hemicrania (migraine pain) and epilepsy in traditional folk medicine (8), the objective of the present study was to investigate the antihyperalgesic effects of the aqueous extract of ST in animal models, which are believed to serve as models of experimental migraine and the relationship of these effects to dopamine receptor antagonism.

\section{Material and Methods}

\section{Plant material and extract preparation}

Pharmacognostically identified dried pericarps of fruits of S. trifoliatus Linn, family Sapindaceae, were collected from the local market and authenticated by Dr. A.M. Mujumdar, Agharkar Research Institute, Pune, India. Aqueous extract of ST was prepared as reported $(5,6)$. Briefly, one hundred grams of the pericarp was soaked in 400 $\mathrm{ml}$ distilled water for $16 \mathrm{~h}$. The percolate was then decanted, centrifuged and filtered through Whatman (No. 1) filter paper to obtain clear extract $(300 \mathrm{ml})$. This process of extraction was repeated again with the same volume of distilled water. The percolates were pooled and lyophilized to give a browncolored powder ( $68 \%$ yield). Acid hydrolysis of the extract yielded only one glycone, which was identified as hederagenin. Therefore, estimation of the saponins present in the extract was calculated as hederagenin. The content of hederagenin was estimated in the extract by boiling it with $50 \%$ methanolic hydrochloric acid. The entire mixture was evaporated to dryness and reconstituted in methanol. HPLC estimation was carried out using Kromasil C- 18 column $(5 \mu \mathrm{m}, 250 \mathrm{~mm}$ x $4.6 \mathrm{~mm})$ with gradient elution $(0.1 \%$ formic acid and acetonitrile in the ratio of 80:20 $\mathrm{v} / \mathrm{v}$ ) and evaporative light scattering detector. The concentration of hederagenin was found to be between 5.61-6.97\% by weight of the extract, which was in accordance with the literature $(6,7)$.

\section{Animals}

Adult male Swiss albino mice weighing 18$22 \mathrm{~g}$ were obtained from the Research Animal Facility of Lupin Ltd., Pune, India. On arrival, the animals were allocated at random to treatment groups in polypropylene cages with paddy husk as bedding. Animals were housed at a temperature of $24 \pm 2^{\circ} \mathrm{C}$ and relative humidity of $65 \%$, on a 12 -h light/12-h dark cycle. All animals had free access to tap water and a standard pelleted laboratory diet.

All the experimental procedures and protocols used in this study were reviewed and approved by the Institutional Animal Care and Use Committee of Lupin Ltd., Pune, 
India, and were in accordance with the guidelines of the Committee for the Purpose of Control and Supervision of Experiments on Animals (CPCSEA), Ministry of Environment and Forests, Government of India. The rules of CPCSEA are implemented according to the guidelines of the Institute of Laboratory Animal Resources (Washington, DC, USA). Experiments were carried out between 9:00 and 17:00 h.

\section{Morphine withdrawal hyperalgesia}

The method of Galeotti et al. (10) was used. Mice were randomly assigned to either a morphine-treated group or one of the two control groups (tap water or 5\% saccharose). Morphine-treated mice received a solution of morphine dissolved in 5\% saccharose solution in water bottles in increasing doses as follows: days 1 and $2,0.1 \mathrm{mg} / \mathrm{ml}$; days 3 and 4, $0.2 \mathrm{mg} / \mathrm{ml}$; days 5 and $6,0.3$ $\mathrm{mg} / \mathrm{ml}$; days $7-15,0.4 \mathrm{mg} / \mathrm{ml}$. On day 15 , the morphine and saccharose solutions were replaced with tap water at a time referred to as $0 \mathrm{~h}$. Six hours after the replacement with water, mice showed a significant reduction of pain threshold in the hot-plate test.

Hot-plate test. The hot-plate test was used to measure the latencies according to the method described by Ghelardini et al. (11). Animals were placed on a hot plate maintained at $55 \pm 1^{\circ} \mathrm{C}$ and the time between placement of the animal on the hot plate and the occurrence of either licking of the fore or hind paws was recorded as response latency. Reaction times (seconds) were measured before (pre-test) and after treatment. The end point used was the licking of the fore or hind paws. The mice scoring below 12 and over $25 \mathrm{~s}$ in the pre-test were rejected. An arbitrary cut-off time of $45 \mathrm{~s}$ was adopted. The licking latency values were recorded at 15 - and 30-min intervals from $6 \mathrm{~h}$ postmorphine removal. ST extract (2 and $10 \mathrm{mg}$ / $\mathrm{kg}$, ip $)$ and prochlorperazine $(0.5 \mathrm{mg} / \mathrm{kg}$, ip $)$ were administered $15 \mathrm{~min}$ and $45 \mathrm{~min}$, re- spectively, before the 6-h test period following morphine removal. The effect of ST and prochlorperazine was compared to the effect of saline in control animals.

\section{Acetic acid-induced abdominal constrictions}

The abdominal constrictions resulting from ip injection of $0.3 \%$ acetic acid, half the percentage described by Koster et al. (12), consist of constriction of abdominal muscle together with stretching of hind limbs. ST (2 and $10 \mathrm{mg} / \mathrm{kg})$ and prochlorperazine $(0.5$ $\mathrm{mg} / \mathrm{kg}$ ) were administered ip 15 and $45 \mathrm{~min}$ before acetic acid injection and the number of abdominal constrictions was counted for $15 \mathrm{~min}$. Antihyperalgesia is reported as the number of abdominal constrictions observed during the 15-min interval subsequent to the injection of the irritant. Comparisons were made between control animals treated with saline and animals pretreated with the extract or prochlorperazine.

\section{Dopamine antagonism: apomorphine-induced climbing}

The method of Chung et al. (13) was followed. Briefly, each mouse was placed in a cylindrical wire-mesh cage (height $13 \mathrm{~cm}$, diameter $14 \mathrm{~cm}$ and mesh size $3 \mathrm{~mm}$ ) for 1 $\mathrm{h}$ prior to the experiments. ST $(2,10,20$, or $100 \mathrm{mg} / \mathrm{kg}, i p)$ or haloperidol $(1 \mathrm{mg} / \mathrm{kg}, i p)$ were administered $30 \mathrm{~min}$ prior to the administration of apomorphine $(2.5 \mathrm{mg} / \mathrm{kg}, i p)$. Climbing behavior was assessed at 5-min intervals up to $20 \mathrm{~min}$, starting $10 \mathrm{~min}$ after apomorphine administration using the following scoring system: 0 , no paws on the cage; 1 , two paws on the cage; 2 , four paws on the cage. The score recorded for each animal was based on the position of the animal at the time when it was first observed. The total time spent climbing on the cage was also recorded for each animal. An observer unaware of the specific treatments recorded the observations. 


\section{Radioligand receptor binding studies}

The radioligand receptor binding studies were carried out by NovaScreen Biosciences

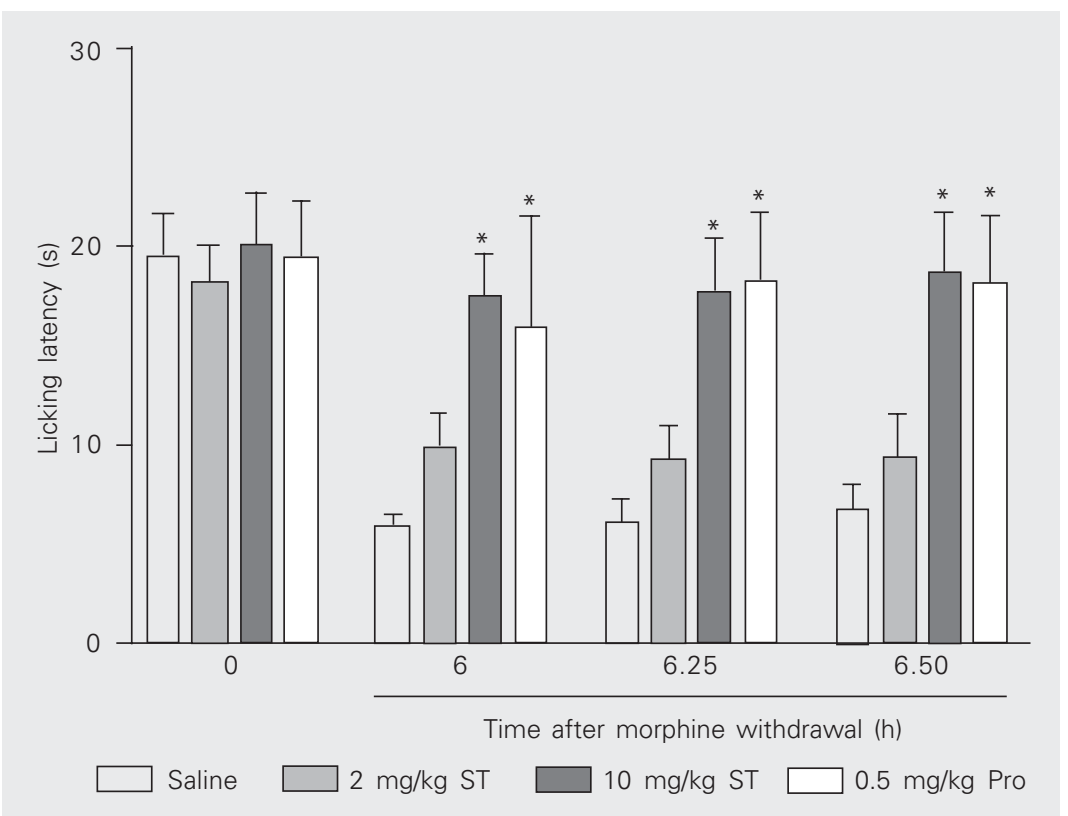

Figure 1. Effect of Sapindus trifoliatus (ST) extract at 2 and $10 \mathrm{mg} / \mathrm{kg}$, ip, on morphine withdrawal hyperalgesia. Each column indicates the mean \pm SEM, in seconds, of the hotplate licking latency for 10 mice. Pro $=$ prochlorperazine. ${ }^{*} \mathrm{P}<0.05$ compared with salinetreated animals (ANOVA followed by Dunnetts' test).

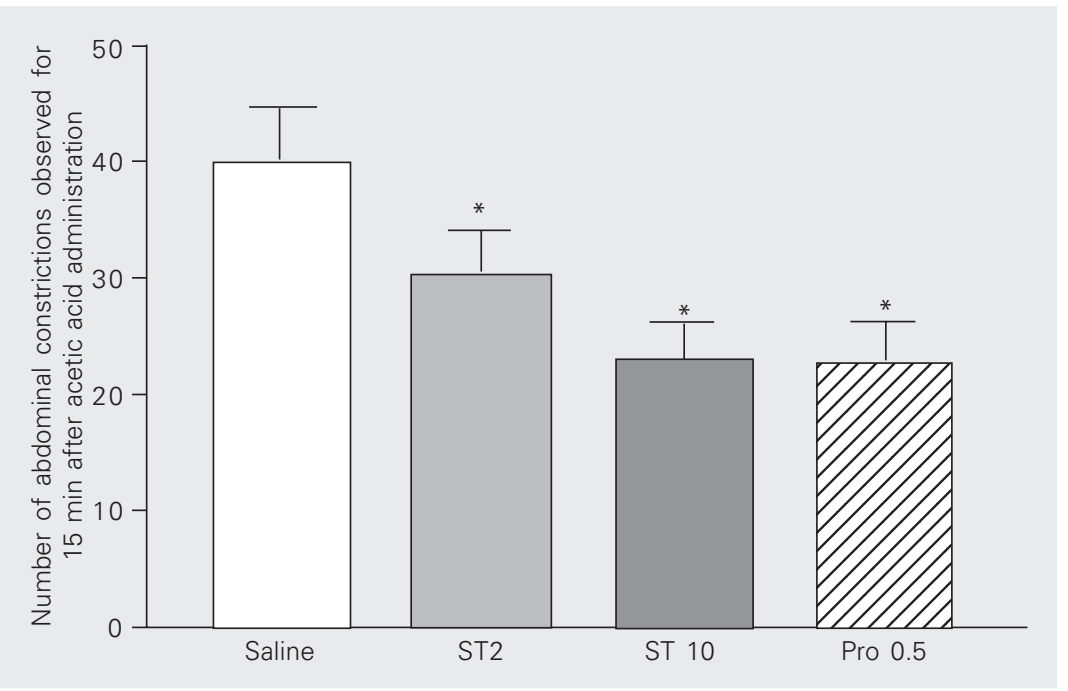

Figure 2. Effect of Sapindus trifoliatus extract at 2 (ST 2) and $10 \mathrm{mg} / \mathrm{kg}$ (ST 10), ip, on $0.3 \%$ acetic acid-induced abdominal constrictions. Each column indicates the mean \pm SEM of the number of constrictions exhibited by 10 mice for 15 min after acetic acid injection. Pro $0.5=0.5 \mathrm{mg} / \mathrm{kg}$ prochlorperazine. ${ }^{*} \mathrm{P}<0.001$ compared with saline-treated animals (ANOVA followed by Dunnetts' test).
Corporation, Hanover, MD, USA. The studies were done as per the standard protocols reported elsewhere (www.novascreen.com; 14-16).

\section{Statistical analysis}

Data are reported as means \pm SEM. The statistical significance of the differences between mean values was determined by ANOVA and Dunnett's test. A P value of $<0.05$ was considered to be significant.

\section{Results}

\section{Effect of ST on morphine withdrawal hyperalgesia in the hot-plate test}

Morphine withdrawal syndrome (6 h after morphine withdrawal) significantly reduced the licking latency in mice (with respect to the licking latency observed at $0 \mathrm{~h}$ ). Pre-treatment of the animals with ST extract (2 and $10 \mathrm{mg} / \mathrm{kg}$, ip) and prochlorperazine increased the licking latency in the hot-plate test (Figure 1). However, the increase in latency responses to ip treatment with 10 $\mathrm{mg} / \mathrm{kg}$ of the extract and to treatment with prochlorperazine $(0.5 \mathrm{mg} / \mathrm{kg}$, ip $)$ was significant higher $(\mathrm{P}<0.05)$ compared to saline treatment.

Effect of ST on acetic acid-induced abdominal constrictions in mice

The results of the abdominal constriction test are shown in Figure 2. Administration of 2 or $10 \mathrm{mg} / \mathrm{kg}$ ST or $0.5 \mathrm{mg} / \mathrm{kg}$ prochlorperazine elicited a significant $(\mathrm{P}<0.001)$ decrease in the number of abdominal constrictions in the acetic acid test compared to control animals treated with saline.

\section{Effect of ST on apomorphine-induced climbing}

$\mathrm{ST}$ at doses of 2 and $10 \mathrm{mg} / \mathrm{kg}$, ip, did not 
show any significant inhibition of apomorphine-induced climbing (data not shown), whereas doses of 20 and $100 \mathrm{mg} / \mathrm{kg}$, ip, and haloperidol $(1 \mathrm{mg} / \mathrm{kg}, i p)$ significantly $(\mathrm{P}<$ 0.05-0.001) inhibited the apomorphine-induced climbing behavior in mice (Figure 3A and B).

\section{Receptor ligand binding studies}

ST at the concentration of $250 \mu \mathrm{g} / \mathrm{ml}$ exhibited $104.54 \%$ inhibition at dopamine $\mathrm{D}_{2}$ receptors using rat striata as receptor source.

\section{Discussion}

We have reported that ST at doses of 20 and $100 \mathrm{mg} / \mathrm{kg}$, ip, has a profound analgesic effect in various pain models (17). Despite the observations that ST is effective in the treatment of hemicrania in folk medicine (8), there are no published reports of the effect of ST on experimental migraine models. The pathogenesis of pain in migraine is not completely understood. The key factors are the cranial blood vessels and peripheral trigeminal activation (evidenced by release of calcitonin-gene-related-peptide (CGRP), a vasodilator) (18); however, the mechanism of pain generation is not clear. Studies on animals suggest that pain may be caused by a sterile neurogenic inflammatory process in the dura mater (19), but these results and interpretations cannot be extrapolated to man (20). Since in vivo models of migraine were not available, an experimental mouse model corresponding to human migraine pain was established (11). The present model was based on the observation that morphine withdrawal syndrome is characterized by hyperalgesia very similar to the reduction of pain threshold characteristic of migraineurs (11). The potential antimigraine agents sumatriptan and ergotamine were effective in this model (10). Moreover, the doses required to elicit antihyperalgesia were several-fold lower than the corresponding analgesic doses $(10,11,21)$.
Hyperalgesia induced by ip injection of a $0.3 \%$ acetic acid solution is a model in which the antihyperalgesic activity of sumatriptan and ergotamine has been proved (10). Furthermore, the fact that morphine, which is not useful in the treatment of migraine, was also inactive against the $0.3 \%$ acetic acidinduced abdominal constrictions provides support to the view that this test is a valid experimental migraine model (10). The results of the present study showed that ST

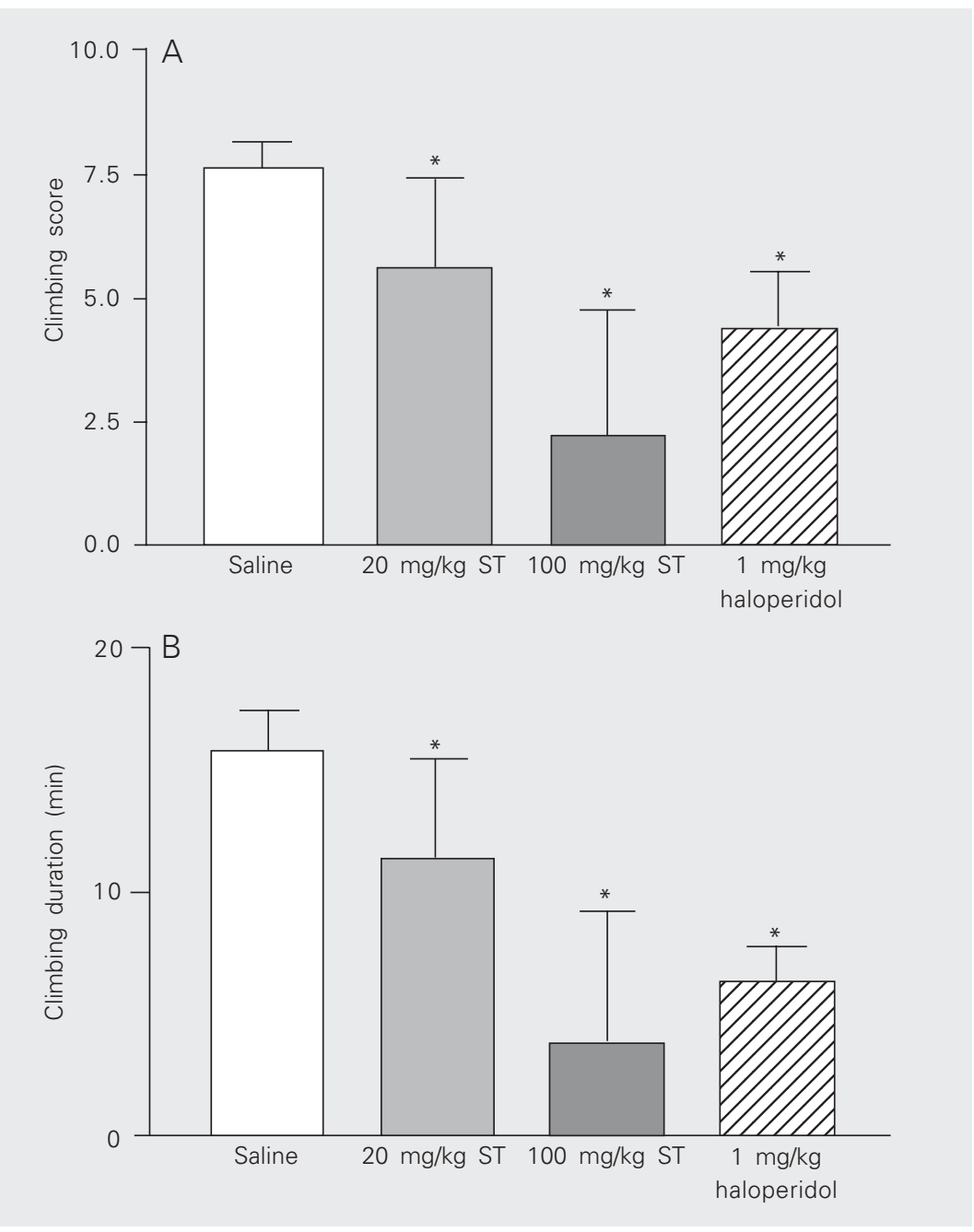

Figure 3. Effect of Sapindus trifoliatus extract at 20 and $100 \mathrm{mg} / \mathrm{kg}$, ip, and haloperidol (1 $\mathrm{mg} / \mathrm{kg}, i p)$ on climbing behavior induced by apomorphine $(2.5 \mathrm{mg} / \mathrm{kg}, i p)$. Each column indicates the mean \pm SEM of the total climbing score for groups of 10 mice. $A$, Climbing score was assessed at 5-min intervals for $20 \mathrm{~min}$, starting $10 \mathrm{~min}$ after apomorphine administration. A score of 10 is the maximum possible. $B$, Total time (min) spent climbing on the cage wall for $20 \mathrm{~min}$, starting $10 \mathrm{~min}$ after apomorphine administration. ${ }^{*} \mathrm{P}<0.05$ compared with saline-treated animals (ANOVA followed by Dunnetts' test). 
and prochlorperazine increased the licking latencies in a statistically significant manner compared to saline-treated animals in morphine removal-induced hyperalgesia in the hot-plate test, and significantly reduced the abdominal constrictions induced by $0.3 \%$ acetic acid. The antihyperalgesic effect of ST was observed at 2 and $10 \mathrm{mg} / \mathrm{kg}$, doses that are 10-fold lower than the analgesic dose (17), which is similar to that of sumatriptan and ergotamine $(21,22)$. In the present investigation, prochlorperazine was used as a reference drug, since dopamine $\mathrm{D}_{2}$ antagonists are useful in the prophylactic treatment of migraine $(23,24)$ and have been reported to be effective in current in vivo models (10). It is interesting to mention that ST exhibited affinity for $\mathrm{D}_{2}$ receptors $(104.54 \%$ at 250 $\mu \mathrm{g} / \mathrm{ml})$ in the receptor ligand binding studies.

A growing body of biological, pharmacological and genetic evidence suggests the role of dopamine in the pathophysiology of certain types of migraine. Most migraine symptoms can be induced by dopaminergic stimulation. Moreover, there is dopamine receptor hypersensitivity in migraineurs, as demonstrated by the induction of yawning, nausea, vomiting, hypotension, and other symptoms of migraine attack by dopaminergic agonists at doses that do not affect nonmigraineurs. Conversely, dopamine receptor antagonists are effective therapeutic agents in migraine (25). Recent genetic data suggest that molecular variations within dopamine receptor genes play a modifying role in the pathophysiology of migraine with aura $(26,27)$.

The apomorphine-induced climbing response is reported to be mediated by activation of both $\mathrm{D}_{1}$ and $\mathrm{D}_{2}$ receptors (28) and $\mathrm{D}_{1}$ and $\mathrm{D}_{2}$ antagonists have been proved to be effective in this model (29).

ST, a phytomedicine known for the treatment of hemicrania, exhibited dopamine-2 antagonism by inhibiting the behavioral symptoms induced by dopamine agonists in the apomorphine-induced climbing behavior model at a dose 10 times higher than that of antihyperalgesic agents. Saponins are known to have sedative and decreased locomotor activity in experimental animals $(30,31)$. It is therefore probable that the saponin component of the ST extract might be contributing in part to the observed pharmacological activities. The present data justify the ethnomedical use of ST in the treatment of hemicrania.

\section{Acknowledgments}

The authors wish to thank Drs. V. Srivastava and S.K. Joshi (Lupin Research Park, Pune, India) for help with the extraction procedure and Dr. N. Sridhar (University of Toronto, Toronto, Canada) for critical comments about the manuscript. The radioligand binding studies carried out by NovaScreen Biosciences Corporation, Hanover, MD, USA, are hereby acknowledged.

\section{References}

1. Breslau N \& Rasmussen BK (2001). The impact of migraine: epidemiology, risk factors and co-morbidities. Neurology, 56 (Suppl 1): $4-12$.

2. Humphrey PPA, Feniuk MJ \& Perren MJ (1998). GR 43175, a selective $5-\mathrm{HT}_{1}$-like receptor agonist in isolated dog saphenous vein. British Journal of Pharmacology, 94: 1123-1132.

3. Humphrey PPA, Feniuk W \& Perren MJ (1990). Antimigraine drugs in development: Advances in serotonin receptor pharmacology. Headache, 30 (Suppl 1): 12-16.

4. Amrey WK (1983). Flunarizine, calcium channel blocker: a new prophylactic drug in migraine. Headache, 23: 70-74.
5. Rogers KL, Grice ID \& Griffiths LR (2000). Inhibition of platelet aggregation and $5-\mathrm{HT}$ release by extracts of Australian plants used traditionally as headache treatments. European Journal of Pharmaceutical Sciences, 9: 355-363.

6. Gupta DR \& Ahmed B (1990). Emarginatosides B and C: Two new saponins from Sapindus emarginatus fruits. Indian Journal of Chemistry, 29B: 268-270

7. Kanchanapoom T, Kasai R \& Yamasaki K (2001). Acetylated triterpene saponins from the Thai medicinal plant Sapindus emarginatus. Chemical and Pharmaceutical Bulletin, 49: 11951197. 
8. Kritikar KR \& Basu BD (1999). Indian Medicinal Plants. Vol. 1. International Book Distributors, New Delhi, India, 632-635.

9. Jain NK \& Kulkarni SK (1999). Antinociceptive and anti-inflammatory effects of Tanacetum parthenium L. extract in mice and rats. Journal of Ethnopharmacology, 6: 251-259.

10. Galeotti N, Ghelardini C, Grazioli I \& Uslenghi C (2002). Indomethacin, caffeine and prochlorperazine alone and combined revert hyperalgesia in in vivo models of migraine. Pharmacological Research, 46: 245-250.

11. Ghelardini C, Galeotti N, Donaldson S \& Bartolini A (1998). The antimigraine drug ergotamine is endowed with antihyperalgesic activity. Phytotherapy Research, 12: S10-S12.

12. Koster R, Anderson M \& De Beer EJ (1975). Acetic acid analgesic screening. Federation Proceedings, 18: 412-413.

13. Chung IW, Moore NA, Kang UG \& Kim YS (2002). Behavioral pharmacology of polygalasaponins indicates potential antipsychotic efficacy. Pharmacology, Biochemistry, and Behavior, 71: 191-195.

14. Bylund DB \& Toews ML (1993). Radioligand binding methods: practical guide and tips. American Journal of Physiology, 265: L421-L429.

15. Bylund DB \& Murrin LC (2000). Radioligand saturation binding experiments over large concentration ranges. Life Sciences, 67: 2897-2911.

16. Zhu M, Bowery NG, Greengrass DM \& Phillipson JD (1996). Application of radioligand receptor binding assays in the search for CNS active principles from Chinese medicinal plants. Journal of Ethnopharmacology, 54: 153-164

17. Arulmozhi DK, Veeranjaneyulu A, Bodhankar SL \& Arora SK (2004). Investigations into the antinociceptive activity of Sapindus trifoliatus in various pain models. Journal of Pharmacy and Pharmacology, 56: 655-661.

18. Goadsby PJ, Edvinsson L \& Ekman R (1990). Release of vasoactive peptides in the extracerebral circulation of humans and the cat during activation of the trigeminal system. Annals of Neurology, 23: 193-196.

19. Moskowitz MA \& Cutrer FM (1997). Attacking migraine headache from beginning to end. Neurology, 49: 1193-1195.

20. May A, Shepheard SL, Knorr M, Effert R, Wessing A, Hargreaves RJ, Goadsby PJ \& Diener HC (1998). Retinal plasma extravasation in animals but not in humans: implications for the pathophysiology of migraine. Brain, 121: 1231-1237.

21. Ghelardini C, Galeotti N, Donaldson S, Nicolodi M, Sicuteri F \& Bartolini A (1996). Prevention by sumatriptan of hyperalgesia induced by morphine withdrawal. Fundamental and Clinical Pharmacology, 10: 192 (Abstract).

22. Ghelardini C, Galeotti N, Fignini M, Imperato A, Nicolodi M, Sicuteri F, Gessa GL \& Bartoloni A (1996). The central cholinergic system has a role in the antinociception induced in rodents and guinea pigs by the antimigraine drug sumatriptan. Journal of Pharmacology and Experimental Therapeutics, 279: 884-890.

23. Jones J, Sklar D, Dougherty J \& White W (1989). Randomized double-blind trial of intravenous prochlorperazine for the treatment of acute headache. Journal of the American Medical Association, 261: 1174-1176.

24. Cuppola M, Yealy DM \& Leibold RA (1986). Randomized placebocontrolled evaluation of prochlorperazine versus metoclopromide for emergency treatment of migraine headache. Annals of Emergency Medicine, 26: 541-546.

25. Peroutka SJ (1997). Dopamine and migraine. Neurology, 49: 650656.

26. Ophoff RA, Van den Maagdenberg AM, Roon KI, Ferrari MD \& Frantus RR (2001). The impact of pharmacogenetics for migraine. European Journal of Pharmacology, 9: 1-10.

27. Cerbo R, Barbanti P, Bizzi MG, Fabbrini G, Brusa L, Roberti C, Zanette E \& Lenzi GL (1997). Dopamine hypersensitivity in migraine: role of the apomorphine test. Clinical Neuropharmacology, 20: $36-41$.

28. Moore WA \& Axton MS (1990). The role of multiple dopamine receptors in apomorphine and N-n-propylnorapomorphine-induced climbing and hypothermia. European Journal of Pharmacology, 178: 195-201.

29. Vasse M, Chagraoui A \& Protais P (1998). Climbing and stereotyped behavior in mice required stimulation of $D_{1}$-dopamine receptors. European Journal of Pharmacology, 148: 221-229.

30. Wagner H, Ott S, Jurcic K, Morton J \& Neszmelyi A (1983). Chemistry, 12C NMR study and pharmacology of two saponins from Colubrina asiatica. Planta Medica, 48: 136-141.

31. Dubios MA, Ilyas M \& Wagner $H$ (1986). Cussnosides A and B, two triterpene saponins from Cussonia barteri. Planta Medica, 56: 8083 